\title{
Shaping of Face Toothing in Flat Spiroid Gears
}

\author{
Roman Staniek \\ Poznan University of Technology, Poland
}

The paper deals with the theoretical basics of forming the face toothings in flat wheels of spiroid gears by means of a single cutting edge tool, using NC machine tools. Based on kinematics geometrical formulas, geometrical models of creating the tooth spaces, as well as a determination of the modification depth along the tooth line, are described. Equations of the tooth line have been calculated as well as mathematical formulas enabling the determination of the modification depth, assuming the correct matching of the worm with the flat wheel of the spiroid gear.

Based on geometrical models and mathematical formulas algorithms were elaborated in order to determine the envelope condition and modification depth of the tooth line. Then, on the basis of algorithms, computer programs that are going to be used to design the flat spiroid gears and to calculate their geometrical dimensions were proposed. The modification depth along the tooth line was also illustrated.

The simulation results have been illustrated by the gear example.

Finally, two methods of machining the face toothings in spiroid gears with a single edge-cutting tool are presented: accurate and approximate ones. Based on algorithms and programs, a comparative simulation of both methods was elaborated.

(C)2011 Journal of Mechanical Engineering. All rights reserved.

Keywords: NC rotary tables, flat spiroid gears, forming of toothings, modification, simulation

\section{INTRODUCTION}

Spiroid gears, especially their flat variety, are often applied in rotary tables as mechanical reduction gears [1], [3] to [6] and [11]. This increased application can be observed in a new generation of NC gear cutting machine tools [6], [11] and [12].

In a flat spiroid gear, a worm engages the wheel with face toothing. The tooth line depends on the worm direction (right hand or left hand worm) and the direction of inclination in the wheel (right hand or left hand direction) and it is a modified involute line:

- a shortened involute line in case of conformable directions,

- an elongated involute line in case of opposite directions.

It has been assumed that the worm profile in axial section is a straight line which enables the application of the same cutting edge (cutting insert) to machine the worm and the flat wheel [7].

The face toothing of the flat spiroid gear should be formed with a tool of the profile and dimensions of the engaging worm. Such a tool, formed as a hob, is very expensive and has to be prepared for each individually designed worm [2], [9] and [12].
A much cheaper solution is a single edge cutting tool in the form of an insert made of sintered carbides with a profile equivalent to the worm tooth profile. The profile conformity should occur only in the range of the convolution intersection of the worm and the face toothing wheel. The same simple insert made of sintered carbides may be used to form both the worm and the wheel. Based on such an assumption, it is not necessary to define a pitch as the unit describing the measure of the tooth profile [7] and [12].

\section{TOOTH LINE EQUATION}

The tooth line equation in the face section provided at the distance $h_{0}$ from the tool axis (see Fig. 1) was obtained in the following way:

- in a fixed coordinate system $(x, y)$ with an origin located in the rotary table axis a parametric equation of the cutting edge track (spindle rotation angle $\varphi$ is treated as the parameter) was determined,

- the equation of this track was determined in a polar coordinate system $\left(R_{y}, \Phi\right)$ assuming as the origin the middle of the wheel (rotary table axis) and a line connecting the middle of the cutting edge profile with the table axis in the initial position of the tool $\left(x_{0}=0 ; \varphi=0\right)$, 
- by a variation of the $x_{0}$ two-parametric family of cutting edge tracks were obtained and then the searched tooth line was determined as the envelope of the twoparametric family curves.

The track of the cutting tool edge in the rectangular coordinate system $(x, y)$ with an origin in the middle of the rotary table may be described with the following parametric equations (Fig. 1):

$$
\left.\begin{array}{l}
x=x_{0}+\left(r_{0}-\frac{h_{0}}{\cos \phi}\right) \cdot \operatorname{tg} \alpha \\
y=a_{0}-h_{0} \cdot \operatorname{tg} \phi
\end{array}\right\} .
$$

The equation of the other side track is obtained by applying a negative value of the profile angle $\alpha$.

In a polar coordinate system $\left(R_{y}, \Phi\right)$ (see Fig. 2), the set of equations can be obtained in the form:

$$
\left.\begin{array}{l}
R_{y}=\sqrt{x^{2}+y^{2}} \\
\Phi=\operatorname{arctg} \frac{x}{y}+\frac{k}{z} \cdot \phi-\frac{x_{0}}{R_{w}}
\end{array}\right\} .
$$

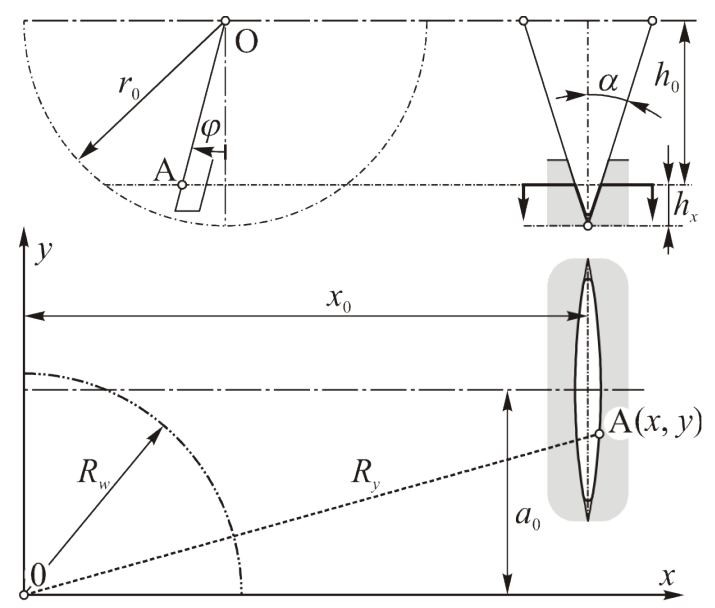

Fig. 1. Geometrical model of forming the tooth space in a fixed coordinate system $(x, y)$

The second equation concerning the $\Phi$ value is composed of factors describing the place of the origin. The directions of the worm and the involute tooth line in the wheel are considered by coefficient $k$ :

- $\quad k=+1$ for conformable directions (a shortened involute is obtained),
- $k=-1$ for opposite directions (an elongated involute is obtained).

The variation of the parameter $x_{0}$ in the equation set (2) creates the family of curves for those the envelope has to fulfil the condition:

$$
\left|\begin{array}{ll}
\frac{\partial R_{y}}{\partial \phi} & \frac{\partial \Phi}{\partial \phi} \\
\frac{\partial R_{y}}{\partial x_{0}} & \frac{\partial \Phi}{\partial x_{0}}
\end{array}\right|=0
$$

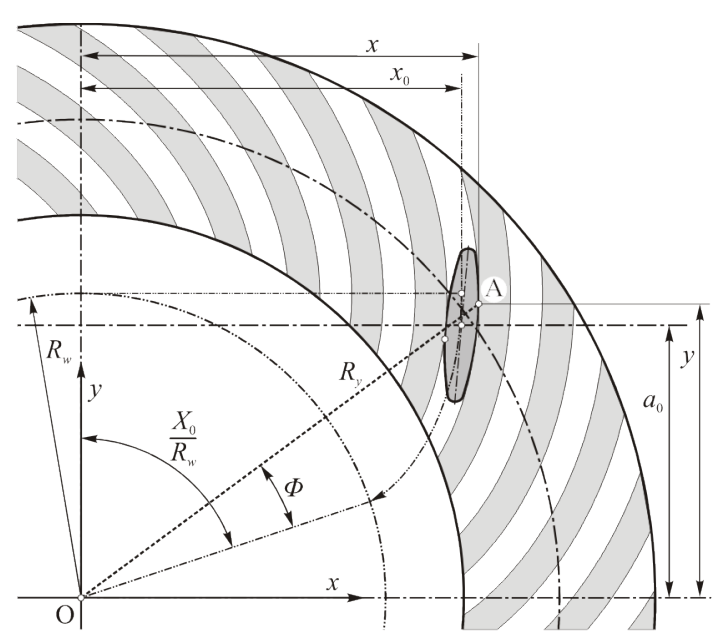

Fig. 2. Geometrical model of forming the tooth spaces in a coordination system of a machined wheel

Partial derivatives that are necessary to calculate the determinant (3) can be obtained from Eqs. (1) and (2):

$$
\begin{gathered}
\frac{\partial R_{y}}{\partial \phi}=\frac{1}{R_{y}} \cdot\left(\frac{\partial x}{\partial \phi} \cdot x+\frac{\partial y}{\partial \phi} \cdot y\right) \\
\frac{\partial \Phi}{\partial \phi}=\frac{1}{R_{y}^{2}} \cdot\left(\frac{\partial x}{\partial \phi} \cdot y+\frac{\partial y}{\partial \phi} \cdot x\right)+\frac{k}{z} \\
\frac{\partial R_{y}}{\partial x_{0}}=\frac{x}{R_{y}} ; \quad \frac{\partial \Phi}{\partial x_{0}}=\frac{y}{R_{y}^{2}}-\frac{1}{R_{w}} \\
\frac{\partial x}{\partial \phi}=\frac{h_{0} \cdot \operatorname{tg} \alpha \cdot \sin \phi}{\cos ^{2} \phi} \mid \\
\frac{\partial y}{\partial \phi}=\frac{h_{0}}{\cos ^{2} \phi}
\end{gathered}
$$

After substitution Eqs. (4) and (5) into the determinant (3) it is possible to obtain the envelope condition: 


$$
\frac{R_{w}-y}{x}+\frac{R_{w} \cdot k}{z \cdot h_{0}} \cdot \cos ^{2} \phi-\operatorname{tg} \alpha \cdot \sin \phi=0 .
$$

The depth of the tooth line modification was determined in the axial plane of the tool which is rectangular to the pitch plane of the flat wheel (see Fig. 3.) The modification depth is the distance $\Delta$ between the track point of the tool cutting edge and the point of the tooth side in the flat wheel.
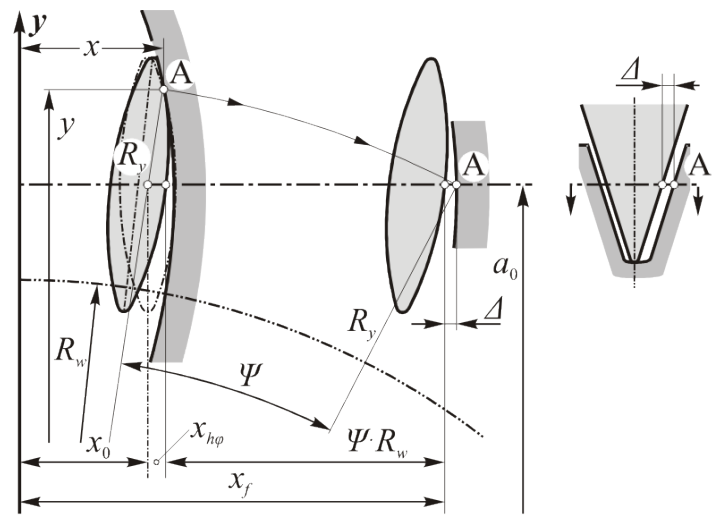

Fig. 3. Geometrical model for determining the depth of the modification value of the tooth line

The point A of the tooth side was determined as the envelope point in another tool position (point A located at the left side of the Fig. $3)$. The tool edge creating this point had the rake surface turned at the angle $\varphi$ (see Fig. 1). The value of $x_{h \varphi}$ (see Fig. 3) is the algebraic sum of half of the tool edge track width and the displacement of the tooth line in indexing move while turning the tool at the angle $\varphi$ :

$$
x_{h \phi}=\left(r_{0}-h_{0}\right) \cdot \operatorname{tg} \alpha-\frac{k \cdot \phi}{z} \cdot R_{w},
$$

and the angle $\Psi$ is obtained from:

$$
\Psi=\arccos \frac{a_{0}}{R_{y}}-\operatorname{arctg} \frac{x}{y} .
$$

The modification depth $\Delta$ is determined in relation to $x_{f}$ (see Fig. 3) obtained from:

$$
x_{f}=x_{0}+x_{h \phi}+\Psi \cdot R_{w},
$$

and then $\Delta$ is obtained from:

$$
\Delta=\sqrt{R_{y}^{2}-a_{0}^{2}}-x_{f} .
$$

Due to the compatibility of worm and tool dimensions, the modification depth is obtained in order to assure the correct engagement of the worm with the flat wheel of the spiroid gear.

The above mentioned dependencies were calculated assuming the exact representation of the tool cutting edge, without the consideration of displacements caused by system flexibility and cutting forces.

\section{DETERMINATION OF THE TOOTH MODIFICATION DEPTH}

As mentioned above, the tooth line of the flat wheel may be obtained as the elongated or shortened involute. The straight line of the cutting edge forms the useful part of the tooth line. Close to the generating circle (with radius $R_{w}$, see Fig. 4) the concave tooth side may be formed by the round corner of the cutting edge. This part of the tooth cannot be engaged with the worm and is useless.
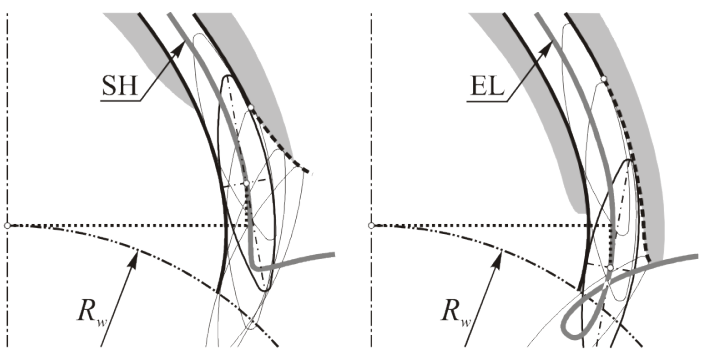

Fig. 4. Forming (undercutting) of the concave tooth side with the round corner of the cutting edge: SH-shortened involute, EL-elongated involute; the broken line shows the part of the tooth line formed by the round corner of the cutting edge

Fig. 5 depicts a geometrical model for calculating the rotation angle of the tool when the tooth line, at the section at a distance of $h_{0}$ from the tool axis, is represented as the envelope of tracks obtained from the straight line section of the cutting edge.

According to the above model it possible to calculate the boundary radius of the tool profile applying the Eq.:

$$
r_{l}=r_{0}-\rho_{0} \cdot\left(\frac{1}{\sin \alpha}-\sin \alpha\right),
$$


and the boundary angle of tool rotation, applying the equation:

$$
\phi_{l}=\arccos \frac{h_{0}}{r_{l}} .
$$

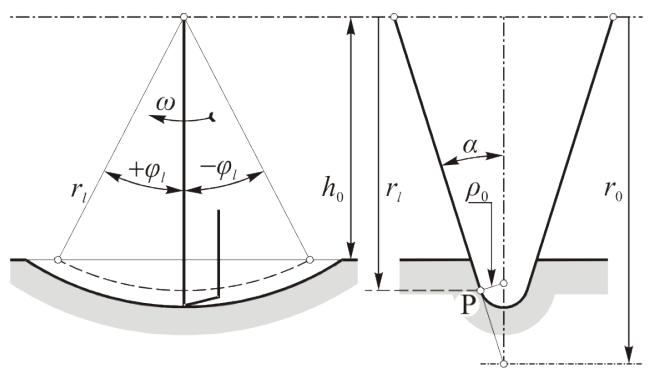

Fig. 5. Geometrical model for calculation of the boundary angle of the rotating tool that forms the tooth side surface with the straight line of the cutting edge

In the program for calculating the depth modification of the tooth line the following assumptions have been considered:

- tooth line is formed as the envelope of the cutting edge tracks when the envelope condition is fulfilled for the angle $\varphi$ from the range $-\varphi_{l} \leq \varphi \leq+\varphi_{l}$

- tooth line is represented by point $\mathrm{P}$ of the tool profile when the condition of the envelope of the cutting edge tracks would demand elongation of the straight part of the cutting edge over point $\mathrm{P}$; in such case it has been assumed that $\varphi=\varphi_{l}$, and the representation of the round corner cutting edge was not calculated, as this part of the tooth side is not engaged with the worm.

An algorithm of obtaining the depth modification needs multiple calculations of the envelope condition. The angle $\varphi$, when the envelope condition is fulfilled (this means $\mathrm{W}=$ 0 ), is obtained by applying the iterative method. This part of the program was treated as a separate procedure (see Fig. 6).

The tooth line modification depth $\Delta$ was calculated in the face cross-section at distance $h_{0}$ when the middle point of the cutting edge profile was located at the distance $x_{0}$ from the wheel axis (see Figs. 2 and 3). The algorithm for calculating the modification depth is presented in Fig. 7.

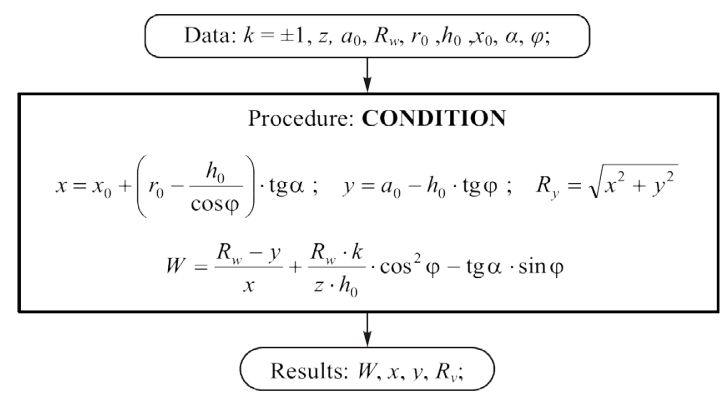

Fig. 6. Algorithm for calculating the envelope condition

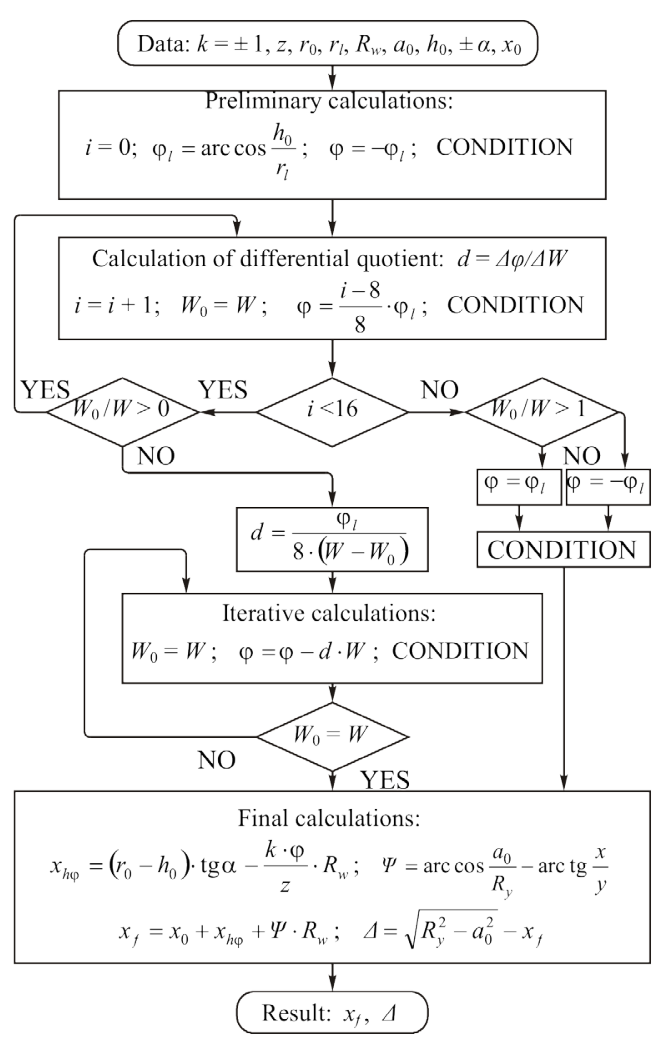

Fig. 7. Algorithm for calculating the modification depth for the tooth line of the flat wheel in the spiroid gear

By applying the positive value of the profile angle $\alpha$ for the concave side and the negative value for the convex side, it is possible to obtain the modification depth value for both tooth sides.

The proper value of the tool rotation angle $\varphi$ was calculated by means of the iterative method when the envelope condition (see Eq. 6) was fulfilled. The following values of the angle 
$\varphi$ were determined by means of Newton's secant method. In the first part of the algorithm (see Fig. 7) the iterative coefficient was determined. This coefficient is obtained as the quotient of angle $\varphi$ increment and the increment of the polynomial value $W$ (left side of Eq. 6) which is calculated in the neighbourhood of the zero value for $W$.

The range of angle $\varphi\left(-\varphi_{l},+\varphi_{l}\right)$ was divided into 16 parts. For the following values of $\varphi$ the $W$ value was calculated and the antecedent value was marked as $W_{0}$. The indicator showing the existence of the zero value in the investigated sub-range is the negative quotient $W_{0} / W$. The method of calculating the value of the angle $\varphi$ which fulfils the envelope condition is presented in the second part of the algorithm.

In case the tooth line is formed by the round corner of the cutting edge, it was assumed that the tooth line is the representation boundary point $\mathrm{P}$ tracks of the straight line cutting edge (see Fig. 5). In this case the boundary angle $\varphi=\varphi_{l}$ (positive or negative).

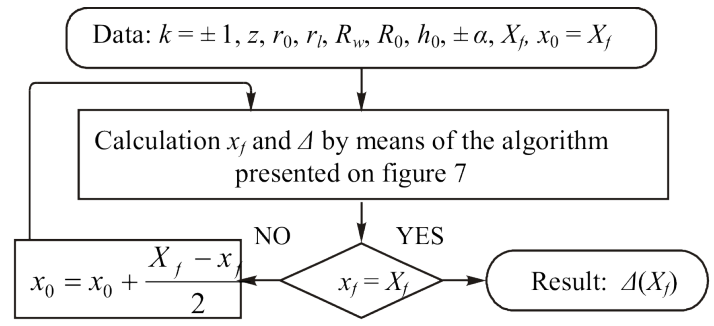

Fig. 8. Algorithm for calculating the tooth line modification depth of the flat wheel as the function of the nominal point distance line from the toothing axis

The graphical or numerical presentation of calculation results as the function $\Delta\left(x_{f}\right)$ is much easier when $x_{f}$ is treated as an independent value. In order to do this, the calculations presented in Fig. 7 should be repeated in an additional loop by means of a simple iterative method. The algorithm of these calculations is presented in Fig. 8 .

The range of the independent value $X_{f}$ was obtained by taking into consideration the possible engagement of the worm with the flat wheel teeth. This range is approximately the distance between points of intersection the worm axis with internal cylinder (with radius $R_{i}$ ) and the external cylinder (with radius $R_{e}$ ) of the flat wheel (see Fig. 9).

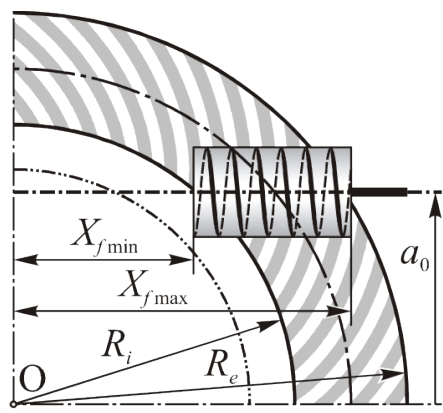

Fig. 9. The range of the independent value $X_{f}$

Based on the described algorithms a computer program was elaborated in order to calculate parameters of the flat spiroid gear and to illustrate tooth modification. Calculation results are presented in Fig. 10 with the gear applied in the rotary table FNd $320 \mathrm{~s}$ as an example.

The zero line of the modification depth (marked in Fig. 10 as " 0 ") is created where the cutting edge track is tangential to the point located on the tool (worm) axis projection line that is projected on the surface of the investigated face cross section. In this point the worm lead angle (on the co-axial cylinder with radius $h_{0}$ ) is equal to the angle created by the normal to the tooth line with the projection of the worm (or tool) axis on the cross-section plane.

The distance $X_{f}(\Delta=0)$ of the zero modification depth line from the toothing axis is determined by the dependency:

$$
X_{f}(\Delta=0)=\frac{2 \cdot \pi \cdot k \cdot\left(a_{0}-R_{w}\right)}{p} \cdot h_{0} .
$$

The modification depth of the concave tooth side is much greater than the convex tooth side, so Fig. 11 shows the modification distribution on the concave tooth side (magnification 25:1) for the spiroid gear and for the numerical example shown in Fig. 10. The nominal surface of the tooth side is shadowed.

The tooth side modification was determined as the difference between the worm tooth profile and the flat wheel in the worm axial plane that is rectangular to the pitch of the wheel. The modification depth of the convex tooth side surface is much smaller than the modification depth of the concave tooth side surface. The great values of modification occur close to the internal cylinder of the co-axial engagement. This is the 
position where the tooth line curvature increases and gets closer to the curvature of the cutting edge track in the face cross section of the wheel. This phenomenon as well as a smaller inclination angle of the edge point tracks on the co-axial cylinder with a diameter greater than the pitch diameter makes it possible to obtain that part of the tooth side which was machined with the round cutting edge corner. This small part of the tooth side surface in the neighborhood of the bottom of the tooth is presented in Fig. 11 by the broken line. The computer program and the illustration presented in Fig. 10 facilitate finding the proper geometrical parameters of the spiroid gear and then creating an illustration of the modified tooth side. The program is a very effective tool for designing flat spiroid gears.

\section{METHODS OF FORMING FACE TOOTHINGS IN THE FLAT SPIROID GEAR WITH THE APPLICATION OF A SINGLE EDGE CUTTING TOOL}

The method of forming the face toothing in a flat spiroid gear was elaborated by R. Grajdek [8]. The forming of large flat wheels with the single tool edge equivalent to the diameter of the mating worm needs an application of the long arbor with the cutting insert at the end of it. The rigidity of such a system is very small and therefore in the author's investigations the face toothing was formed on an NC milling machine with the spindle axis inclined to the pitch plane of the wheel at an angle slightly smaller than the angle of the tooth profile. The diameter of the tool

\begin{tabular}{|c|c|c|c|c|c|c|c|c|}
\hline \multicolumn{9}{|c|}{ PLANE SPIROID GEAR } \\
\hline \multicolumn{9}{|c|}{ DIRECTION OF: worm coil / tooth line of wheel - R/R } \\
\hline \multicolumn{2}{|c|}{$\begin{array}{l}\text { WORM: } \\
\text { Number of coil } \\
\text { Axial pitch } \\
\text { Tooth space height } \\
\text { External diameter } \\
\text { Pitch diameter }\end{array}$} & $\begin{array}{l}{[\mathrm{mm}]} \\
{[\mathrm{mm}]} \\
{[\mathrm{mm}]}\end{array}$ & $\begin{array}{l}=1 \\
=6.000 \\
=4.897 \\
=35.000 \\
=31.000\end{array}$ & \multicolumn{2}{|c|}{$\begin{array}{l}\text { FACE TOOTHING: } \\
\text { Number of teeth } \\
\text { Base diameter } \\
\text { Internal diameter } \\
\text { Pitch diameter } \\
\text { External diameter }\end{array}$} & \multicolumn{3}{|c|}{$\begin{aligned} z & =90 \\
{[\mathrm{~mm}] } & =171.887 \\
{[\mathrm{~mm}] } & =214 \\
{[\mathrm{~mm}] } & =239.99 \\
{[\mathrm{~mm}] } & =270\end{aligned}$} \\
\hline \multicolumn{4}{|c|}{ 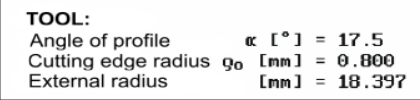 } & \multicolumn{2}{|c|}{$\begin{array}{l}\text { MESHING: } \\
\text { Meshing height } \\
\text { Gear axis distance } \\
\text { Gear ratio }\end{array}$} & \multicolumn{3}{|c|}{$\begin{aligned} {[\mathrm{mm}] } & =4.00 \\
{[\mathrm{~mm}] } & =80.459 \\
\varepsilon & =6.311\end{aligned}$} \\
\hline $\begin{array}{c}\text { Section } \\
\text { height } \\
\text { hv }[\mathrm{mm}]\end{array}$ & \multicolumn{5}{|c|}{$\begin{array}{l}\text { Distance from the current section to the gear axis } x_{1}[\mathrm{~mm}] \\
\mathbf{7 0 . 0 0}\end{array}$} & $\mid \begin{array}{c}\text { Minimum } \\
\text { mod. size } \\
x(0)\end{array}$ & \multirow{2}{*}{\multicolumn{2}{|c|}{\begin{tabular}{|} 
Limit of tooth line \\
modification \\
continuity \\
$\mathrm{x}$ minimum [mm] \\
and limiting \\
modification depth
\end{tabular}}} \\
\hline $\begin{array}{l}\text { hv }[\mathrm{mm}] \\
0.000 \\
1.000 \\
2.000 \\
\text { 3.000 } \\
\text { 4.000 }\end{array}$ & \begin{tabular}{|l|}
\multicolumn{2}{|c|}{$C$} \\
0.000799 \\
0.002250 \\
o.004210 \\
o.006537 \\
o.009127
\end{tabular} & $\begin{array}{l}\text { Zonvex flank } \\
\text { o.000055 } \\
\text { o.000127 } \\
\text { o.000802 } \\
\text { o.001931 } \\
\text { 0.003402 }\end{array}$ & $\begin{array}{l}\text { * Modificati } \\
0.001316 \\
0.000324 \\
0.000002 \\
0.000196 \\
0.000789\end{array}$ & \begin{tabular}{|l|} 
ion size $[\mathrm{mm}]$ \\
0.003619 \\
0.001786 \\
0.000672 \\
0.000119 \\
0.000009
\end{tabular} & \begin{tabular}{|l|}
0.006448 \\
0.003932 \\
0.002181 \\
0.001021 \\
0.000336
\end{tabular} & \begin{tabular}{|c|}
$x(0)$ \\
27.54 \\
83.28 \\
89.02 \\
94.77 \\
100.51
\end{tabular} & & \\
\hline$h \cup[\mathrm{mm}]$ & \multicolumn{4}{|c|}{ Concave flank ${ }^{*}$ Modification size $[\mathrm{mm}]$} & & $x(0)$ & $x$ & Mod. size \\
\hline $\begin{array}{l}0.000 \\
1.000 \\
2.000 \\
3.000 \\
4.000\end{array}$ & $\begin{array}{l}0.002830 \\
0.009093 \\
\text { o.019639 } \\
\text { o.035821 } \\
0.052910\end{array}$ & $\begin{array}{l}0.000164 \\
0.000423 \\
0.002986 \\
0.008099 \\
0.016237\end{array}$ & \begin{tabular}{|l|}
0.003461 \\
0.000932 \\
0.000005 \\
0.000681 \\
0.003044
\end{tabular} & $\begin{array}{l}0.008605 \\
0.004589 \\
0.001869 \\
0.000359 \\
0.000029\end{array}$ & $\begin{array}{l}0.014127 \\
0.009238 \\
0.005489 \\
0.002762 \\
0.000980\end{array}$ & $\begin{array}{r}77.54 \\
83.28 \\
89.02 \\
94.77 \\
100.51\end{array}$ & \begin{tabular}{|l|l|} 
& 55.60 \\
& 57.55 \\
& 60.33 \\
& 64.73 \\
1 & 75.14 \\
\end{tabular} & $\begin{array}{l}0.014343 \\
0.063480 \\
0.084462 \\
0.075626 \\
0.030583\end{array}$ \\
\hline
\end{tabular}

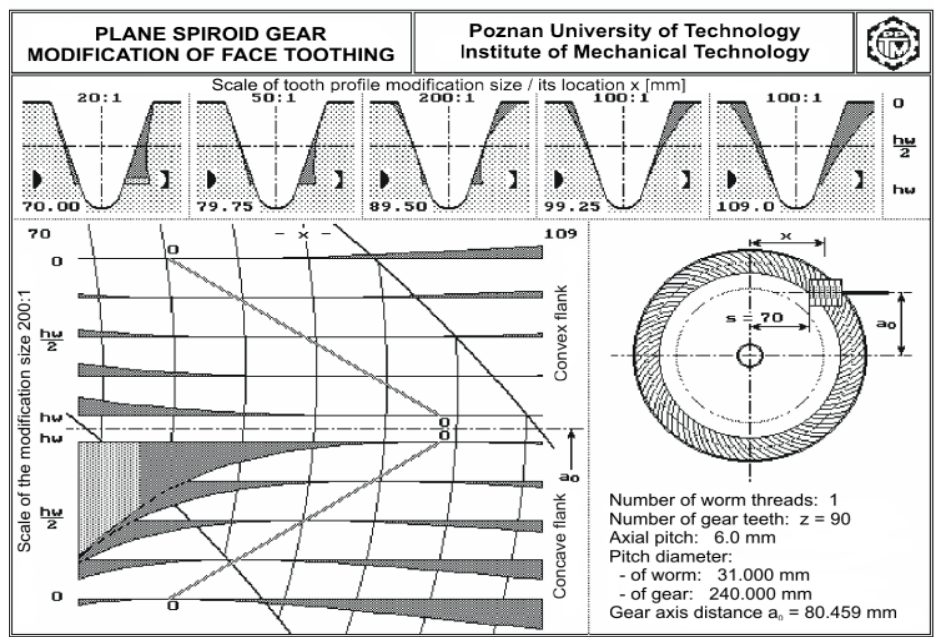

Fig. 10. Illustration of the face toothing modification in the flat spiroid gear (dimension proportions are saved in the picture) 
was calculated in such a way so as to obtain the curvature of the cutting edge track in the pitch plane (from the concave side) as almost equivalent to the curvature obtained by the cross-section of the worm thread with this pitch plane.

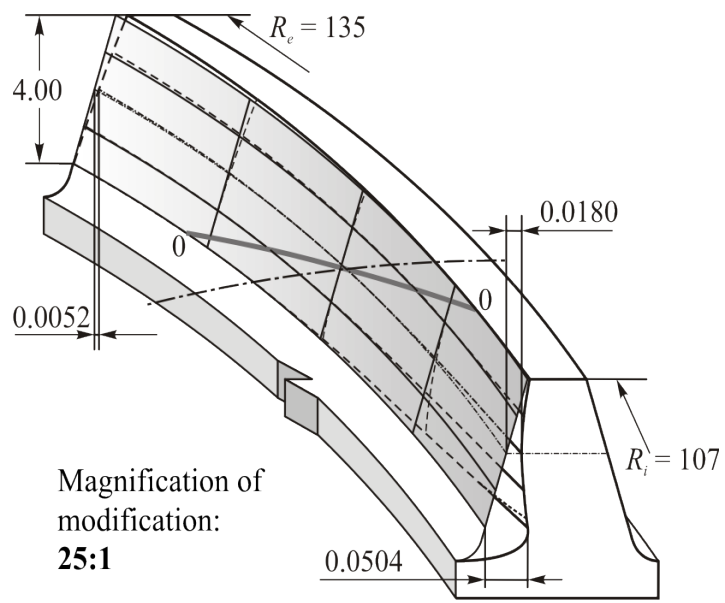

Fig. 11. Distribution of the modification depth on the concave tooth surface of the flat wheel applied in the spiroid gear. This is the spatial illustration of the calculation results presented in Fig. 10

The advantage of this method is the possibility of forming the wheels with any diameter and with a greater diameter of the tool arbor (greater than the diameter of the mating worm). Its disadvantage is the unilateral fixing of the tool arbor which significantly decreases the rigidity.

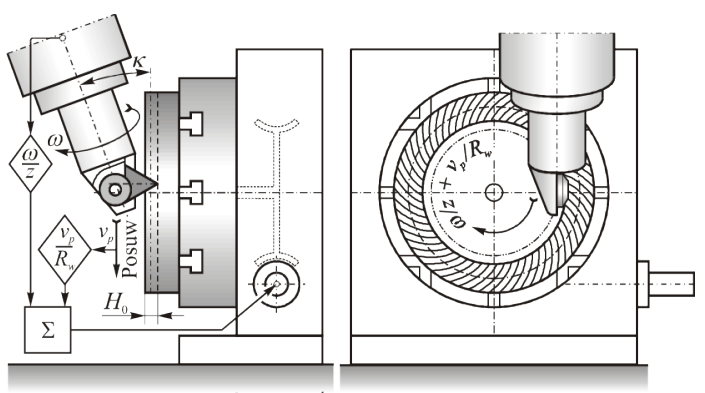

Fig. 12. Forming of face toothing on the $N C$ milling machine with the tool axis inclined to the plane of the machined wheel [8]

The author's original proposal of the tool fixing is presented in Fig. 13. The tool (insert) is fixed in the spindle and supported at the end of the arbor by the needle bearing mounted in a special body, which was fixed with the spindle box body.

The disc of the rotary table is coupled with the spindle of the $\mathrm{NC}$ milling machine by means of an electronic control system with the adder of indexing movement, and generating movement in such a way that the rotation of the disc (with the machined wheel) by one angular pitch is equivalent to:

- one rotation of the tool (indexing movement), - moving of the tool by one axial pitch (generating movement).

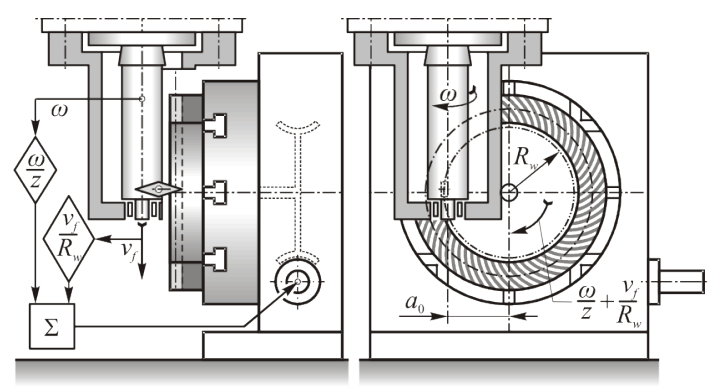

Fig. 13. Forming of the face toothing on the NC milling machine with the spindle axis parallel to the plane of the machined wheel (according to the author's idea) [12]

The tool axis is placed at the same position against the wheel as the worm in the gear. The feed moving is the relative moving of the tool spindle along its axis in rotary table co-ordinations. In reality the feed moving is performed by the rotary table and this is the first component of the generating movement. The second component is performed by the additional rotation of the disc (with the wheel).

This method enables obtaining the exact engagement of the wheel and the worm in the spiroid gear. This fact is the greatest advantage of the method presented.

\section{CONCLUSIONS}

In both methods of forming the face toothings for flat spiroid gears (see Fig. 12 approximate method, and Fig. 13 - exact method) modification depth values were determined as deviations against the theoretical involute profile. 


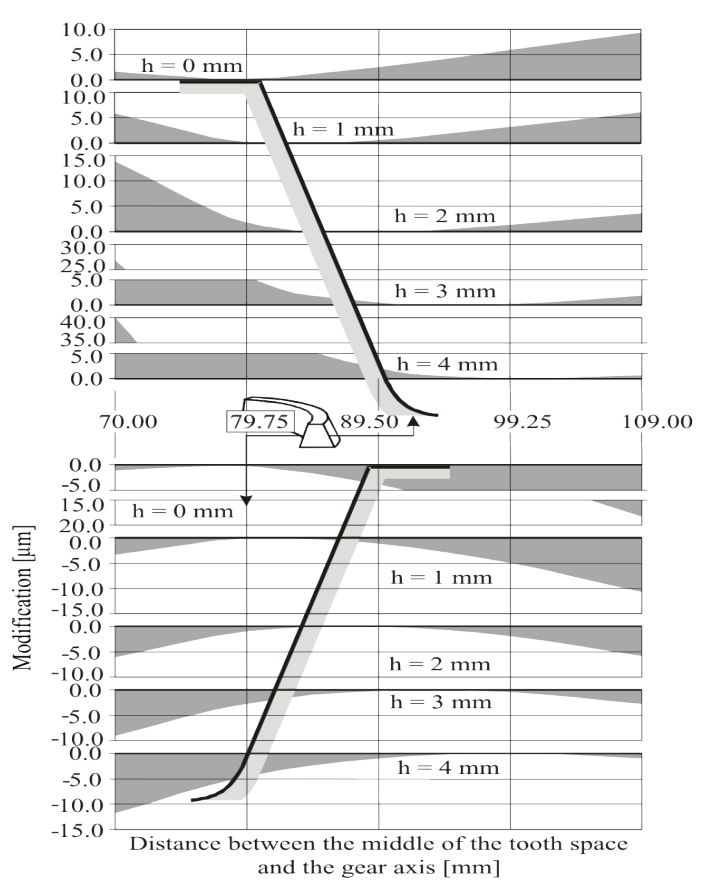

Fig. 14. Deviations of the tooth line modification occurring by machining with the approximate method with the inclined tool axis

Theoretically this aspect is correct. Considering the practical aspects, it seems reasonable to accept as a master profile the profile obtained by machining with the ideal worm by means of an exact method with the tool axis parallel to the wheel plane. It was assumed that in this case modification deviations of the tooth line profile are equal to zero and then the engagement with the real worm should be expected as errorless. Considering the above assumptions in order to evaluate the compatibility of the demanded tooth line and the obtained tooth line according to the method with the inclined tool axis, the proper deviations were calculated. The deviation values for both sides of the tooth concave and convex are presented in Fig. 14. Negative values prove a lack of contact between the worm and the wheel, but positive values demand the lapping process. Both methods were verified experimentally and implemented in the production [12].

\section{REFERENCES}

[1] Abadijev, V. (1994). Aspects of the mathematic modeling of skew-axes gears whose tooth surfaces have a linear contact, Gearing and Transmissions, vol. 2, p. 24-31.

[2] Bolos, V., Bolos, C. (2002). Considerations concerning the roughness resulted from milling plan spiroid worm gears. Proc. of $4^{\text {th }}$ International Conference DMC, Kosice, $\mathrm{p}$. 247-249.

[3] Dudas, I. (1999). Optimization and manufacturing of the spiroid gearing. $4^{\text {th }}$ World Congress Gearing and Power Transmission, Proceedings volume, Paris, $\mathrm{p}$. 377-389.

[4] Dudas, I. (2000). The theory and practice of worm gear drives. Penton Press, London,

[5] Goldfarb, V.I. (1995). Theory of design and practise of development of spiroid gearing, Proc. of Congress: Gear Transmissions, p. 1-5.

[6] Grajdek, R. (2000). Modification of face toothing in a plane spiroid gear. Archives of Mechanical Technology and Automation, vol. 20, no 2, p. 89-97.

[7] Grajdek, R. (1996). The modified face toothing with arc line. Archives of Mechanical Technology and Automation, vol. 16, no 2, p. 73-83.

[8] Grajdek, R. (2000). The face toothings. Theoretical, principles of forming and new applications. Publishing House Poznan University of Technology, Poznan.

[9] Kirov, V. (1999). Design of spiroid hobs, Journal of Materials Processing Technology, vol. 88, no. 1, p. 208-215.

[10] Litvin, F.L., Nava, A., Fan, Q., Fuentes, A. (2002). New geometry of worm face gear drives with conical and cylindrical worms, Generation. Simulation of Meshing and Stress Analysis, U.S. ARMY ARL-CR 0511, NASA/CR-211895.

[11] Litvin, F.L., Petrov, K.M., Gansin, V.A. (1973). The effect of geometrical parameters of hypoid and spiroid gears on its quality characteristics. Mechanism and Machine Theory, vol. 8, no. 2, p. 187-196.

[12] Staniek, R. (2005). NC rotary tables. Theoretical basics, design, technology and investigations, no. 392, Publishing House Poznan University of Technology, Poznan. 